\title{
ТИПОЛОГИЯ ЛЮДЕЙ: ИНТЕРЕСЫ И ПОТРЕБНОСТИ
}

Аннотация. Человеком управляют его интересы и потребности. Сущность человеческого естества можно определить по доминированию его интересов и потребностей. Чтобы возвышать потребности людей, общество нуждается в соответствующей соииальной технологии как системе.

Ключевье слова: психология, этнокультура, человек, потребность, витальные потребности, базовые потребности, высшие потребности, многообразие потребностей, извращённые интересы и потребности.

Богатство, если рассматривать его вещественно, заключается только в многообразии потребностей.

(К. Маркс)

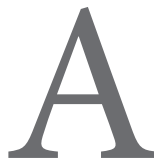

брахам Маслоу, один из основоположников американской гуманистической психологии, внёс огромный вклад в человековедение, создав теорию человеческих потребностей. Он ввёл понятие «базовых потребностей», разработал иерархию потребностей, притом витальные, в числе других базовых потребностей, назвал низшими. По его мнению, базовые потребности являются конституциональными или наследственными ${ }^{1}$. Нельзя не согласиться с ним: тип нервной деятельности и специфика гормональной системы влияют на формирование склонности к той или иной профессии. Особенно с этим необходимо считаться при проведении профориентации: учитывать наличие художественных генов, учитывать предпочтение подвижного или сидячего образа жизни. Говорят о более или менее воинственных этносах. Скажем, финноугры (за всю обозримую историю человечества) предпочитают оседлый образ жизни. Кроме того, отличаются миролюбием и не колонизовали другие нации. Правда, обрусевшие и отатарившиеся финно-угры становятся более воинственными, следовательно, социокультурная среда имеет влияние тоже достаточно сильное.

В пользу инстинктоидности витальных потребностей говорит и материнский инстинкт, который управляет женщиной-матерью не только в период беременности и грудного возраста ребёнка, но и всю жизнь.

Другой пример. Согласно результатам международного исследования 80\% женщин согласны на половую несовместимость, если муж будет добрым и внимательным. Но остальные 20\% ни при каких условиях не со-

1 Маслоу А. Мотивация и личность. СПб, 2001. С. 155-164. гласны жить с мужем при половой несовместимости видимо, так сильно влияют особенности функционирования жёлёз внутренней секреции, преобладают половые инстинкты.

А. Маслоу много внимания уделяет сравнению низших и высших потребностей. И притом отмечает инстинктоидность не только витальных, но и всех потребностей, якобы даже «высшие потребности имеют инстинктоидную природу» ${ }^{2}$. Вполне естественно, что он как гуманист верит в позитивную природу человека. Действительно, человек «задуман» Творцом позитивным существом, но хочется возразить в том, что механизм возвышения потребностей заложен в человеческой природе изначально. Сказано: человек существо общественное. Человеческая природа в отличие от природы животного есть лишь потенциальная возможность, и вне соответствующей социокультурной среды может не проявиться. И утверждение об инстинктоидной природе высших потребностей, о спонтанном переходе от низших потребностей к высшим по мере удовлетворения базовых потребностей, думается, не свободно от фатализма - трудно согласиться, что достаточно удовлетворения базовых потребностей, а высшие сами возникнут спонтанно.

Хочется возразить и категорическому заявлению: «Задача совершенствования природы человека может быть решена только с помощью тех социальных мер, которые укрепляют и поощряют инстинктоидные тенденции человека». Во-первых, не нужно заниматься совершенствованием природы человека (равно как нельзя заниматься совершенствованием Natur-природы, то есть окружающей нас Природы). Во-вторых, говоря, что «высокое возникает и проявляется только на базе

\footnotetext{
2 Там же. С. 163.
} 
низкого» ${ }^{3}$, он явно грешит. Видимо, как гуманист Маслоу хочет сказать власть имущим: если хотите, чтобы народ имел высшие потребности, удовлетворите его базовые потребности. В этой части с ним можно согласиться. Действительно, бедность унижает человека, ухудшает его моральное состояние, травмирует психику. Его унижает не только абсолютная нищета, но и социальное неравенство - относительная нищета. Если уровень жизни низших слоёв отстаёт от элиты, купающейся в роскоши, в 50-100 раз, низкое социальное положение угнетает психику относительно бедного (вовсе не обездоленного) человека, и он посвящает жизнь доказательству своей состоятельности - старается догнать богатых по обладанию престижным автомобилем, коттеджем, яхтой (стараясь соответствовать образу жизни «стопроцентного американца»).

Если полностью следовать логике А. Маслоу, то: a) от бедного человека нельзя ожидать нравственного поведения; б) высшие потребности могут возникнуть только у обеспеченных людей (скажем у аристократии, буржуазии, бизнесменов). В данном случае психологгуманист, веря в позитивное начало человека, льёт воду на мельницу вульгарных материалистов. Кроме того, он явно умаляет роль идейного воспитания, оставляет в тени зависимость поведения человека от пропаганды тех или иных ценностей.

Ретроспективный взгляд обнаруживает, что: a) традиционные крестьяне в годы лихолетья не воровали, не грабили; б) на любовь способны представители всех сословий (и богатых, и бедных); в) среди революционеров, самоотверженно боровшихся с несправедливостью, были люди с разным уровнем удовлетворения витальных потребностей: и крестьяне, и рабочие, и разночинцы, и дворяне, и бывшие царские генералы. На путь освобождения народа от социальной несправедливости встали бывший батрак Нестор Махно, бедный гимназист Владимир Маяковский, крестьянин Василий Чапаев, рабочий Василий Блюхер и многие другие революционеры, выходцы из бедных слоёв царской России.

Скульптор Степан Эрьзя в основном жил в сарае, который одновременно являлся и мастерской, всю жизнь проходил в халате. Женщины около него задерживались недолго (по несколько месяцев, некоторые больше года), отбирали его деньги и скрывались. Его особо не волновали материальные, психологические и социальные проблемы.

Конечно, человек не свободен от материальных нужд, но он принципиально отличается от животного и может служить высокой идее независимо от степени

3 Там же. С. 164. удовлетворённости своих витальных потребностей. Вопрос возвышения потребностей связан с уровнем духовности индивида. Во имя торжества социальной справедливости жертвовали собой не только ратники революции. Во время Великой Отечественной войны по примеру Александра Матросова закрыли грудью амбразуру ДОТов сто шестьдесят бойцов Советской Армии. Звание Героя Советского Союза присвоили только первым, остальные воины, совершившие подобный подвиг, посмертно награждались лишь орденами. И погибали они не ради славы, а ради торжества справедливости, из-за потребности служить ближним и дальним людям. Хочется ещё раз подчеркнуть, что высшие потребности формируются не спонтанно, а под воздействием социокультурной среды (даже при отсутствии удовлетворения витальных потребностей). Высшая потребность может быть не только у того, кто материально обеспечен и чья плоть процветает. И люмпенами духа могут быть не только нищие и бомжи, но и высокопоставленные бюрократы.

Запад умаляет общественную природу человека. Можно полагать, на А. Маслоу оказала влияние американская идеология индивидуализма, и ему трудно представить способность к самопожертвованию тех людей, которые выросли в иной социокультурной среде. Возможно, он хотел сказать, что индивид, не прошедший этап самоутверждения, то есть не имеющий чувства собственного достоинства, не обретает высшие потребности. Если это так, то с ним можно согласиться: действительно, посвятить жизнь поиску истины, стремиться к гармонии, страдать за свою любовь способен только тот человек, которому удалось своевременно самоутвердиться (а кому не удалось, тот жизнь посвящает не достижению высоких идеалов, а самоутверждению).

Ещё один аргумент против логического построения А. Маслоу. США - самая богатая страна в мире, там высок уровень жизни (материального потребления), но американское общество не отличается духовностью. В то же время в бедной Индии уровень духовности гораздо выше. По прогнозам экологов, если всё население земного шара будет потреблять столько, сколько потребляют американцы, ресурсы Земли будут исчерпаны, окружающая среда будет разрушена, человечество погибнет.

Псевдомарксисты СССР рассуждали примерно так же, как А. Маслоу: вначале, мол, надо удовлетворить первичные потребности трудящихся (потребность в пище, одежде, жилище), а затем заниматься формированием высших потребностей. И всуе любили говорить на тему удовлетворения возрастающих потребностей трудящихся. Будущее коммунистическое общество представляли как общество изобилия - а новый чело- 


\section{Психология и психотехника 4(55) • 2013}

век якобы возникнет спонтанно - соответственно не были разработаны политика и социальная технология по формированию ни разумных потребностей, ни потребности трудиться. Детский труд был запрещён под благовидным предлогом: детей нельзя эксплуатировать, «дети - единственный привилегированный класс». Им было невдомёк, что беззаботность порождает бездельников, не уловили, что «праздность - мать всех пороков». И неудивительно, что из общеобразовательной школы и детских домов юноши в большинстве своём выпускались (и выпускаются) инфантильными, ориентированными на потребление.

В СССР счастливыми ощущали себя те карьеристы и конъюнктурщики, которые сумели пристроиться к правительственной «кормушке», и граница развитого социализма проходила по Садовому кольцу Москвы.

Дети - зеркало общества. Согласно результатам социологического исследования, доминирующим мотивом отличной учёбы 85\% учащихся и студентов оказалось желание легко жить. По какой причине? Потому что сложилась такая неофициальная общественная установка. Скажем, учитель цитировал А.С. Пушкина: «Мой друг, Отчизне посвятим души прекрасные порывы», а сам неуспевающему ученику менторским тоном говорил: «Не мне нужна твоя учёба, а тебе самому - если будешь плохо учиться, то будешь работать чернорабочим, будешь копаться в навозе». Между строк его нотации слышится: чернорабочий - неполноценный человек, и смысл жизни заключается в удовлетворении не высших потребностей, а витальных. Индивиду с подобной логикой возражает автор следующих строк: «Дурную услугу оказал бы государству тот, кто нашёл бы средство отпускать ему ежегодно всю ту сумму денег, которая необходима его гражданам для покупки за границей всего, что нужно для самой роскошной жизни.

Если бы люди открыли философский камень, то беда была бы ещё невелика: золото перестало быть монетой. Но если бы они нашли сказочный мешок, из которого выскакивает всё, чего душа пожелает, или изобрели машину, вполне заменяющую всякий труд человека, словом, разом достигли тех результатов, которых добиваются техники и политэкономы, то само развитие человечества остановилось бы: разврат и дикость завладели бы обществом, само общество распалось бы, и не одна политическая экономия (к чему бы она служила тогда?) была бы вычеркнута из списка человеческих знаний: с уничтожением необходимости личного труда сама история должна прекратиться)» ${ }^{4}$.

\footnotetext{
4 Ушинский К.Д. Труд в его психическом и воспитательном значении // Ушинский К.Д. Избранные произведения. М.: Просвещение, 1968. С. 286-287.
}

В советское время большинство детей обеспеченных родителей (в основном высокопоставленных чиновников), пресыщенное материальным потреблением, тянувшееся не к духовности, а к получению удовольствий, было замечено в девиантном поведении. Как известно, следование по пути удовлетворения возрастающих витальных потребностей чревато последствиями: потребности человека, ориентированного на обладание (деньгами, роскошью, властью, женщинами), никогда не насыщаются. Это можно видеть из уровня потребления современных олигархов. Также можно вспомнить примеры деградации любителей острых ощущений (богачей царской России), опустившихся ниже животного уровня. Д.Н. Мамин-Сибиряк в романе «Приваловские миллионы» отразил поиск капиталистами всё новых нечеловеческих удовольствий: «Гуляевский дом в Узле был отделан с царской роскошью. Какая жизнь происходила в этом дворце в наше расчётливое, грошовое время, трудно даже представить; можно сказать только, что русская натура развернулась здесь во всю свою ширь. С утра до ночи в приваловских палатах стоял пир горой, и в этом разливном море угощались званый и незваный. И в то же время в том же самом доме в тайных молениях совершалась постоянная раскольничная служба. Часто и хозяин, и гости прямо с пьяной оргии попадали в моленные и здесь отбивали поклоны до синяков во лбу. Словом, жизнь, не сдерживаемая больше ничем, не знала середины и лилась через край широкой волной, захватывая всё на своём пути. Но обыкновенного мотовства этим неистовым детям природы было мало. Какой-то дикий разгул овладел всеми; на целые десятки вёрст дорога устилается красным сукном, чтобы только проехать по ней пьяной компании на бешеных тройках; лошадей не только поят, но даже моют шампанским; бесчисленные гости располагаются как у себя дома, и их угощают целым гаремом из крепостных красавиц» ${ }^{5}$

Капитализм и сегодня не изменил своей сущности. «Современный капитализм во сто крат богаче материально, но ещё ниже, как бы пропорционально этому несметному богатству, он опустился нравственно. Растление человеческой личности идёт по всем направлениям. На одном полюсе разрушительное воздействие на духовный мир людей так называемой «массовой культуры» дополняется одурманиванием их алкоголем, «сладкой отравой» - наркотиками. Не менее страшным стало всё более широко распространяющееся социальное одиночество. Испорченный

\footnotetext{
5 Мамин-Сибиряк Д.Н. Приваловские миллионы. М., 1981. C. 58.
} 
капитализмом человек сначала пытается уйти в мир грёз, а кончает преждевременным уходом из жизни. На другом полюсе - такая дикая роскошь, которая приваловским героям и во сне не снилась. Квартира на одного из сорока комнат, кровать за 35 тысяч долларов под норковым одеялом, платье за два миллиона франков, отороченный дорогим мехом унитаз с подогревом - это лишь легкие «шалости» нынешних высокопоставленных прожигателей жизни» ${ }^{6}$.

Горе-теоретики КПСС в силу своей полуобразованности и догматического мышления смутно представляли себе образ нового человека, их мировоззрению соответствовал древнеримский принцип «хлеба и зрелищ». Духовная потребность, по их пониманию, должна была удовлетворяться на разного рода зрелищах (на стадионе, в цирке, ДК), через потребление представлений. Они не понимали, что человек преобразовывается в процессе активного отдыха, когда он является субъектом действа, когда сам творит. Например, в условиях традиционной культуры на народных праздниках нет пассивных зрителей - все являются участниками игр, танцев, хороводов и вступают в интерсубъектные отношения.

На словах критикуя бездуховную масс-культуру, чиновники от культуры всё сделали для распространения этой самой масс-культуры в СССР. На мероприятиях (так называемых учреждений культуры) в советское время не было межличностного общения на уровне души. Кстати, нет его и сегодня. Потому что массовики-затейники и клубные работники сами не являются носителями народной культуры. В учебных заведениях картина такая же: процесс обучения направлен на рассудок учащегося и не задевает его душу.

Да, к глубокому сожалению, социалистические идеи в СССР не были претворены в жизнь: на уровне декларации остались права человека и формирование всесторонне и гармонично развитого человека с высокими потребностями. Не был претворён в жизнь основной принцип социализма «От каждого - по способностям, каждому - по труду». Партократы, игнорирующие природу человека, выпестовали новую общность — «человейник» (А.А. Зиновьев), состоящую из людей с лошадиным послушанием, бойко шагающих под красными знамёнами. Ныне те самые представители «человейника» готовы рукоплескать любой пошлости, высмеивающей национальных героев, социалистические идеи, символ серпа и молота и носителей народной культуры.

Чиновники-псевдомарксисты учились чему-нибудь и как-нибудь, но не усвоили, что удовлетворение духовных потребностей связано с деятельностью - с созида-

6 Тараткевич М.В. Человек и его потребности. Минск, 1989. C. 40 нием материальных и духовных ценностей, что уровень духовности человека определяется по его отношению к ближним, особенно дальним людям. Когда человек производит продукты для себя и своих близких, то удовлетворяет низшие (витальные, базовые) потребности, а когда производит для дальних людей, то удовлетворяет духовную потребность (Л.Н. Толстой). Возьмём, к примеру, традиционного крестьянина. Он дённо и нощно трудится, впрок запасается добром и щедро делится им с себе подобными. Видя радость одариваемых, крестьянин сам обогащается душевно и возвышается духовно. Духовность его определяется не по молитве, а по умению радоваться чужой радости.

Завершая критику концепции СССР об удовлетворении возрастающих потребностей и поочерёдном удовлетворении первичных и высших потребностей трудящихся, хочу напомнить ещё один факт, подтверждающий теоретическую несостоятельность руководителей советского государства. Так, на каждом съезде КПСС заслушивали план об увеличении производства средств производства (товары группы А) и товаров народного потребления (товары группы Б). Поскольку у партократии и работников Госплана СССР ориентация была на опережающее производство товаров группы А, они умудрились по производству товаров группы Б довести общество до карточной системы. Таков плачевный результат деятельности людей с линейным мышлением.

$$
\star * *
$$

При типологизации людей по интересам и потребностям я воспользовался концепцией А. Маслоу, но сделал некоторые коррективы. Поскольку он жил в условиях отсутствия традиционной культуры, то низменные страсти, в том числе, наркоманию, игроманию, страсть к обладанию (деньгами, властью, женщинами и т.п.), возможно, считал неизбежным атрибутом цивилизации. Это - во-первых, а во-вторых, он, как типичный американский психолог, старается не задевать демаркацию социальной сферы, ограничившись рамками «чистой» психологии.

Свою типологию я изобразил в виде следующей схемы.

$+2$

человек с высшими потребностями $+1$

рефлексированный человек, находящийся в пограничном состоянии 


\section{Психология и психотехника 4(55) • 2013}

0
человек с доминированием
витальных потребностей
(близок к животному уровню)
человек с извращёнными интересами
и потребностями (злостный психопат)

На схеме обозначены уровни: +2 как высший уровень, -1 как низший уровень, а между ними промежуточные уровни 0 и +1 .

Есть немногочисленный тип людей (уровень +2) с доминированием высших потребностей, бытие которых определяется сознанием, и есть тип людей, ограниченных витальными потребностями (уровень 0).

Кто относится к уровню +1 ? Это те люди, у которых ещё нет доминирования высшей потребности, но есть: потребность в труде, творческая потребность, эстетическая потребность, интерес к окружающему миру и к Вселенной, потребность познать закономерности природы, социума и человека, потребность быть востребованным обществом. Кроме того, есть потребность общения, так как одиночество для человека является самым страшным наказанием. Именно социальной природой человека определяется его потребность иметь социальные связи, ощущать локоть ближнего и быть зависимым от него, потребность кому-то принадлежать, быть любимым и через это обезопасить себя, быть социально защищённым, иметь уверенность в завтрашнем дне, быть объектом социума. Но, поскольку человек по своей природе двойствен, противоречив, то у него ещё есть потребность быть субъектом, потребность быть самодеятельным: вмешиваться в жизнь социума, во всём добиваться торжества гармонии, трудиться, созидать, творить новое, рисковать, экспериментировать (потребность в острых ощущениях). Субъект, разумеется, обречён не только на успех, но и делать ошибки, обречён спотыкаться, даже падать, получать ушибы, раны и соответственно страдать. Таким человек «задуман» Творцом (Природой, Богом).

Почему выше перечисленные потребности человека (отличающиеся от животных потребностей) нельзя относить к высшим потребностям? Потому что наличия этих потребностей недостаточно, чтобы называться настоящим человеком. Например, эстетическая и познавательная потребности были развиты и у фашистов, но эти потребности сами по себе не способствовали возвышению их к истинно человеческой природе. Скажем, среди фашистов были и врачи, осуществлявшие различные эксперименты над людьми, в том числе испытывавшие действие отравляющих веществ (OB).
Какие же потребности можно назвать высшими? А. Маслоу, как обычный американец, к высшим потребностям причисляет потребность в самовыражении, в самоактуализации, потребность обретения индивидуальности ${ }^{7}$.

В моём понимании такое определение занижает природу человека, я к высшим потребностям отношу потребность духовно совершенствоваться. Сущность духовности, в конечном счёте, сводится к милосердию, связанному с самопожертвованием. Это форма любви не только к ближним, но и дальним людям, ко всему человечеству. Благодаря милосердию человек обретает радость, мудрость доброты, спокойную совесть, энергию жизни, становится истинно красивым. И через удовлетворение подобных высоких потребностей происходит самореализация личности, раскрытие человеческой потенции.

Разумеется, люди с доминированием высших потребностей (уровня +2) не лишены витальных потребностей, это не аскеты, им доступно удовольствие (счастье потребления), но по-настоящему счастливыми они ощущают себя лишь при удовлетворении высших потребностей.

«Счастье» представителей уровня 0, ограниченных рамками борьбы за существование, рамками карьеры и продолжения рода, заключается в адаптации к меняющимся социальным условиям. Это - конъюнктурщики, неоднородные в своём составе. Среди них есть индивиды, действующие в рамках закона. Есть и нарушающие законы, известные как коррупционеры, злоупотребляющие своим служебным положением, и другие лица с отклоняющимся поведением. Их сознание определяется бытием, ощущениями и инстинктами. По этой причине основная часть приспособленцев (при соответствующих условиях) легко может опуститься до беспринципности и предательства. В качестве примера можно рассматривать коллаборционистов. Так, в власовской армии (РОА) было 5 генералов. Они не случайно дослужились до такого высокого звания - были профессионалами, обладали соответствующими качествами военного организатора. Сам А.А. Власов был успешным советским полководцем, получил признание, славу, был награждён орденом Ленина и двумя орденами Красного Знамени. Однако слава не возвышает человеческие потребности, а, наобо-

На Западе считается нормальным явлением, если человек жизнь посвящает достижению не высокой цели, а обретению биологической индивидуальности или попаданию в Книгу Гиннеса (по крепости зубов, по количеству съеденных бутербродов, метров съеденной крапивы...). Согласно утверждению Э. Фромма, по истинно человеческим качествам американцы не могут похвастаться наличием социальной индивидуальности — глобализация нивелирует грани личности. 
рот, может способствовать обретению нарциссизма. На стороне Германии Власов тоже проявил себя: за боевые действия против советских войск на Одере награждён Железным крестом и немецкими медалями. Притом ни от какой награды не отказался - видимо, каждая награда давала ему жизненную энергию. Выходит, если человек действует согласно своим доминирующим интересам и потребностям, то становится энергичным. Так можно объяснить «чёрную» энергию приспособленцев, конъюнктурщиков, бандитов и других индивидов, отошедших от своей человеческой природы. К ним могут примкнуть артисты, художники, спортсмены, которым безразлично кому служить. И, если в нашей цивилизации стремление к славе, званиям, должностям, власти, наживе не осуждается, а считается нормальным явлением, то можно представить себе, как много ещё надо работать над изменением ценностной ориентации общества.

Власовцы незаметно для себя опустились до абсолютной безнравственности. Их можно отнести к низшему уровню -1 , на котором находятся злостные психопаты (маньяки, воры в законе, рецидивисты, криминальные авторитеты, киллеры, руководители мафиози, тираны, диктаторы, фашисты, некрофилы, садисты, холуи). Это люди с извращёнными интересами и потребностями, опустившиеся ниже животного уровня. Индивид с извращёнными интересами и потребностями не способен критически оценить своё психическое состояние и лишь при приложении длительных усилий психотерапевта может излечиться от психопатии.

Совокупность интересов и потребностей определяет социальную направленность личности, степень ценности её для общества. Истинная ценность человека определяется не должностями и званиями, а его высшими потребностями и их удовлетворением. Коллаборционизм власовцев был предопределён, и их конец оказался вполне логичным: если человек не имеет высших потребностей, если в его жизни главное - карьера, если им управляет бытие, а не сознание, если он ограничен витальными потребностями, то нравственных тормозов не имеет и может эксплуатировать любую идею ради безбедного (физиологического) существования.

Власов, его генералы и офицеры солдат (и себя) обманывали: якобы борются со сталинщиной, с большевизмом. Но убивали они не Сталина, и не партократов, а своих соплеменников, рядовых тружеников, одетых в форму советских солдат. Самообман длился недолго: на суде Власов признался, что, попав в плен, смалодушничал.

У представителя уровня -1, перешедшего черту, отделяющую его от макросоциума, самосознание качественно меняется - происходит деградация личности. Он не способен критически оценить своё состояние, не способен самостоятельно работать над собой и стремиться возвышать свои потребности. Человек же, обретший высшие потребности, в своём самосовершенствовании как бы совершает качественный скачок становится цельной личностью и никогда не опустится ниже своего уровня +2 , ни при каких обстоятельствах не изменит своим принципам и убеждениям, никогда не позволит себе нарушить писаные и неписаные правила и нормы общежития.

Если хочешь узнать человека, выяви его интересы и потребности. По словам К. Маркса, человека определяют и насилуют его собственные потребности ${ }^{8}$. Сущность человека есть совокупность его интересов и потребностей каковы интересы и потребности индивида, таков он сам. Человек в своих действиях руководствуется интересами и потребностями, по их многообразию и возвышенности можно судить о богатстве его внутреннего мира. Если это так, то важно управлять процессом формирования интересов и потребностей ребёнка. Поддерживать в нём интерес к познанию и пониманию окружающего мира, людей и самого себя, стремление совершенствоваться, стремление приносить пользу людям, радовать их.

Хочется напомнить, что интересы и потребности людей формируются целенаправленно. Сегодня забыты советские гуманистические ценности, и новый перестроечный человек с упоением смотрит теле-шоу, киносериалы, детективы, вестерны, эстрадные концерты, слушает информацию о перманентных взрывах, убийствах, авариях. В связи с этим хочу воспроизвести рассказ одной японки по имени Кумико, научного сотрудника из Минска. Когда я учился в Москве в аспирантуре, она проходила стажировку в одном из институтов АН СССР. Родилась она в Южном Сахалине, оккупированном в начале XIX в. века японцами. После окончания Великой Отечественной войны японцам, проживающим на острове, предложили уехать на свою историческую Родину или переселиться на материк СССР. Взрослые из семьи Кумико решили уехать в Японию, а Кумико категорически отказалась. Из-за неё вся семья вынуждена была остаться в СССР и переехать во Владивосток, - кроме бабушки, которая была самурайкой и не могла поменять своего мировоззрения, поэтому вернулась на свою историческую Родину. Дети же стали равноправными советскими людьми: Кумико выросла и вышла замуж за белоруса, а братья «пустили корни» в Москве и Ленинграде.

Мать Кумико впоследствии радовалась, что семья не уехала из СССР. Раз в несколько лет она навещала

8 Маркс К., Энгельс Ф. Соч. 1940. Т. 46. С. 192. 


\section{Психология и психотехника 4(55) • 2013}

свою мать в Японии и видела контраст в ценностной ориентации СССР и Японии. Рассказывала, как в Японии телевидение заполонено рекламой товаров, пропагандой вестерна, показом кинобоевиков, сообщениями о пожарах и убийствах. Вернулась в Советский Союз, и не нарадуется - у нас по телевидению детский хор поёт!

Нужно сказать, что высшая потребность появляется с возникновением любви (к конкретному человеку, людям, родной природе, поиску истины, гармонии).
Самая возвышенная потребность - это потребность быть полезным людям, служить людям. Духовный человек ощущает себя счастливым, именно принеся пользу совершенно незнакомым людям. Жизнь «превозносит, как самого счастливого, того, кто принёс счастье наибольшему количеству людей» (К. Маркс). К сожалению, проблема формирования высших потребностей у нас решается эпизодическими мерами, а нужна система, подобная этнокультуре, нужны микросоциумы, подобные общине.

\section{Сиисок литературь:}

1. Мамин-Сибиряк Д.Н. Приваловские миллионы. М., 1981.

2. Маркс К., Энгельс Ф. Соч. Т. 46.

3. Маслоу А. Мотивация и личность. СПб., 2001.

4. Тараткевич М.В. Человек и его потребности. Минск, 1989.

5. Ушинский К.Д. Труд в его психическом и воспитательном значении // Избранные произведения. М.: Просвещение, 1968.

\section{References (transliteration):}

1. Mamin-Sibiryak D.N. Privalovskie milliony. M., 1981.

2. Marks K., Engel's F. Soch. T. 46.

3. Maslou A. Motivatsiya i lichnost'. SPb, 2001.

4. Taratkevich M.V. Chelovek i ego potrebnosti. Minsk, 1989.

5. Ushinskiy K.D. Trud v ego psikhicheskom i vospitatel'nom znachenii // Izbrannye proizvedeniya. M.: Prosveshchenie, 1968. 